\title{
A Review on Qualitative and Quantitative Analysis of Carbohydrates Extracted from Bacteria
}

\section{Shukla Pooja, Meghani Sonali, Patel Charmi, Shah Dhrumi, Rathod Zalak R* and Saraf Meenu $S$}

Department of Microbiology and Biotechnology, School of Science, Gujarat

University, Gujarat, India

*Corresponding Author: Rathod Zalak R, Department of Microbiology and

Biotechnology, School of Science, Gujarat University, Gujarat, India.
Received: January 28, 2022

Published: February 22, 2022

(C) All rights are reserved by Rathod Zalak R., et al.

\begin{abstract}
Carbohydrate analysis is significant for a variety of reasons. To determine the compositions of foods, beverages, and their constituents, qualitative and quantitative analysis is used. Ingredient labels with precise compositional information are ensured via qualitative examination. Quantitative analysis guarantees that added components on ingredient labels are listed in the correct order. Quantitative analysis also ensures that the amounts of specific consumer-interest components, such as -glucan, are correct and that caloric content can be calculated. To authenticate (i.e., detect adulteration of) food ingredients and products, both qualitative and quantitative analyses can be applied. Developing a carbohydrate analysis system that can be utilized across animal species could improve the utility of analytes and the amount of data we can collect on carbohydrate dietary effects. Sugars, fructans, insoluble fibre, and soluble fibre are some nutritionally important groups of carbohydrates that may be useful to evaluate based on quantities present in diets and apparent impacts on animal performance.
\end{abstract}

Keywords: Analysis; Carbohydrate; DNSA (3, 5, dinitrosalicylic acid); Reducing Sugar; Total Carbohydrate

\section{Introduction}

Carbohydrates are a significant source of energy for us and an important component of our diet. The majority of the foods in our diet contain a high proportion of carbohydrate. Also carbohydrates serve as extracellular structural elements as in cell wall of microbes like bacteria and also in plant and animal [2]. In the cell walls of bacteria insoluble carbohydrate polymers function as structural and protective elements. Carbohydrates are determined as the polyhydroxy aldehydes or polyhydroxy ketones. $\mathrm{Cn}\left(\mathrm{H}_{2} \mathrm{O}\right)$ $\mathrm{n}$ is the chemical formula for carbohydrate, which is an organic biomolecule. As the major constituent, carbohydrate is made up of three atoms: carbon, hydrogen, and oxygen, with a 2:1 ratio of hydrogen to oxygen. Because of the important significance of polysaccharides as macronutrients, primary constituents of dietary fi- bre, food structure components contributing to sensory qualities, and food additives, carbohydrate analysis is very important in the food science [4]. The qualitative analysis of carbohydrates is an important test for detecting and characterising carbohydrates based on colour changes and chemical reactions [2]. The enzymatic approach used has significant advantages in terms of specificity and ease of use.

Qualitative analysis of carbohydrate

There are different test is use in qualitative analysis of carbohydrate like Molisch test, Benedict's test, Silver mirror test (Tollen's reagent), Iodine test, Barfoed's test, Resorcinol (seliwanoff's test). In qualitative analysis result is obtained based on the formation of specific complex due to some reactions, which is detected by changes in the colour of the sample solution. 


\section{Molisch test}

Molisch test is used to distinguish between carbohydrates and non- carbohydrates. It is the preliminary test used to detect the presence of carbohydrates in a sample [24].

\section{Principle}

Molisch's test, which is based on the dehydration reaction, identifies carbohydrate content. By adding concentrated $\mathrm{H}_{2} \mathrm{SO}_{4}$, the carbohydrates in the sample are dehydrated and converted to aldehyde. Furfural (made by the dehydration of pentoses or pentosans) or hydroxymethylfurfural (generated by the dehydration of pentoses or pentosans) are the aldehydes which are created (produced by the dehydration of hexoses or hexosans). The Molisch reagent's contain $\alpha$-naphthol which interacts with the aldehyde to produce a purple colour condensation product $[10,24]$.

\section{Reagents}

Molisch reagent, Sample, Concentrated $\mathrm{H}_{2} \mathrm{SO}_{4}$.

\section{Procedure}

Add 1 drop of Molisch's reagent (10 percent -naphthol in ethanol) to $2 \mathrm{~mL}$ of a sample solution present in a test tube. Pour 1-2 $\mathrm{mL}$ of concentrated $\mathrm{H}_{2} \mathrm{SO}_{4}$ down the edge of the test tube, forming a layer at the bottom. Compare your results to a control (which contain water instead of test sample) by observing the purple colour complex at the interface between two layers [16].

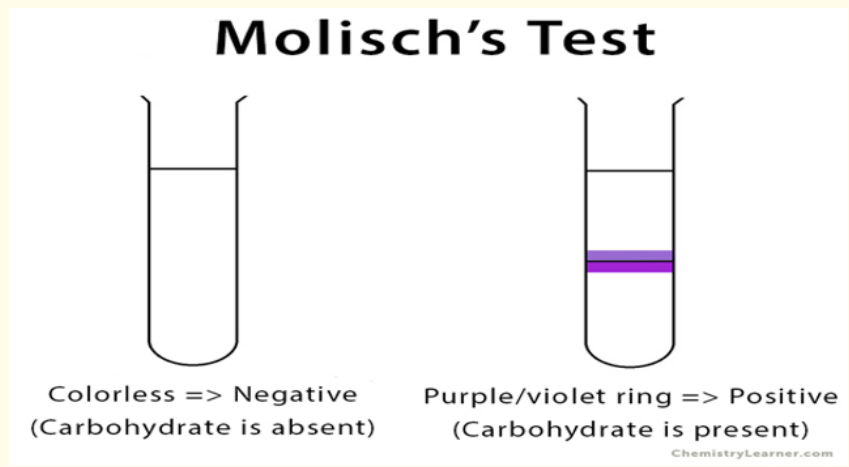

Figure 1: Molisch's test.

https://www.chemistrylearner.com/molischs-test.html

\section{Benedict's test}

Benedict test is use for identifies reducing sugars, which have free ketone or aldehyde functional group [3,24].
Principle

By interacting with an alkaline reagent, such as Benedict's solution, the reducing sugar will be converted to enediols. Depending on the sugar content, the reducing sugar produces a green to brick red precipitate. The colour shift is caused by the reduction of copper (II) to copper (I) in the solution, which results in the formation of a red-colored precipitate. The resulting precipitate is insoluble in water. The alkalinity in the redox reaction solution is provided or maintained by the sodium carbonate. Sodium citrate bind to copper- II ions, preventing copper I reduction $[3,16]$.

\section{Reagent}

Benedict reagent, Test sample.

\section{Procedure}

Make a $1 \mathrm{~mL}$ solution by a test sample. In the same test tube, pour $2 \mathrm{~mL}$ of Benedict's solution. Then boil it in a water bath, for 3-5 minutes. Keep an eye on the test tube for the formation of brick red precipitate [16].

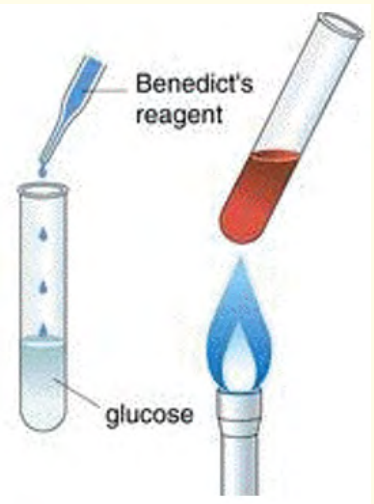

Figure 2: Benedict's test. https://studyhippo.com/testing-for-molecules/

\section{Silver mirror test (Tollen's test)}

This test is given positive by reducing sugars. Detect presence of aldehyde containing carbohydrates also differentiate them from ketone containing carbohydrates [9].

\section{Principle}

Tollen's reagent (ammoniacal solution of silver nitrate) reacts with reducing sugars or aldehydes to create free silver metal. This 
reagent is an alkaline solution of silver nitrate $\left(\mathrm{AgNO}_{3}\right)$ dissolved in liquid ammonia $\left(\mathrm{NH}_{3}\right)$ that forms a complex. When $\mathrm{AgNO}_{3}$ combines with $\mathrm{NaOH}$, a brown precipitates of silver oxide $\left(\mathrm{Ag}_{2} \mathrm{O}\right)$ is produced. Aqueous ammonia dissolves silver oxide, forming the combination $\left[\mathrm{Ag}\left(\mathrm{NH}_{3}\right)_{2}\right] \mathrm{NO}_{3}$. Tollen's reagent contains this complex, which is a strong oxidizing agent that converts the aldehyde group in certain carbohydrates to a carboxylic acid. The reagent's silver ions are reduced to free metallic silver, which produces a silver mirror on the test tube's bottom and sides.

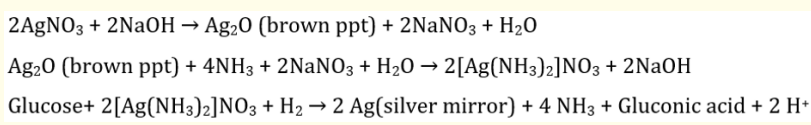

Figure 3: Mechanism of Silver mirror test.

https://microbenotes.com/tollens-test/

\section{Reagent}

Tollen's reagent, Test sample.

\section{Procedure}

Take two clean, dry test tubes and fill one with $1 \mathrm{ml}$ of the test sample and the other with $1 \mathrm{ml}$ of distilled water as a blank. To both test tubes, add $2 \mathrm{~mL}$ Tollen's reagent. Put both the test tube in hot water bath. If a dark grey precipitate e or silver mirror is formed on the bottom and sided of test tube, it indicates the positive result for silver mirror test. Also it confirms the presence of reducing sugar or aldose or $\alpha$-hydroxy ketoses in the given test sample [8].

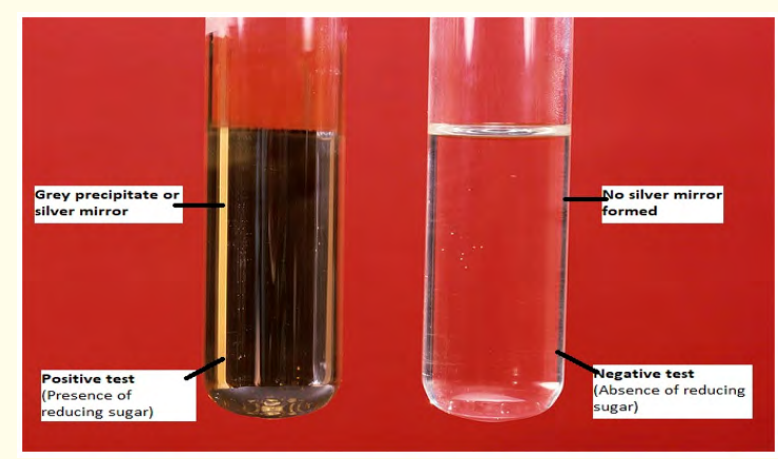

Figure 4: Silver mirror test.

https://onlinesciencenotes.com/tollens-test-or-silver-mirrortest-principle-requirements-procedure-result-interpretationand-limitations/
Iodine test

An iodine test can be used for the detection of starch in a given sample. Also use for differentiate between starch, glycogen, and carbohydrates [9].

\section{Principle}

When starch reacts with $\mathrm{I}_{2}$, it generates an absorbed molecule that is blue in colour. Colour fades with heat or the addition of an alkali such as $\mathrm{NaOH}$ or $\mathrm{KIH}$. This process is just a physical interaction in which $\mathrm{I}_{2}$ binds to the polysaccharide's coiled shape. The coiled structure becomes linear when heated or alkali is added, the absorptive property of polysaccharides decreases and the $\mathrm{I}_{2}$ molecules become free from polysaccharide's coiled structure so the colour disappear [24].

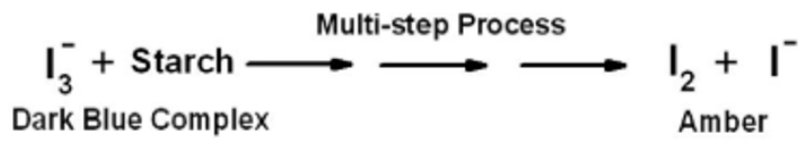

Figure 5: Mechanism of Iodine test.

https://coolgyan.org/chemistry/tests-of-carbohydrates/

\section{Reagent}

Iodine solution, Test sample.

\section{Procedure}

Take the $2 \mathrm{ml}$ of test sample in one test tube and $2 \mathrm{ml}$ of water in another test tube act as control. Add 2-3 drops of iodine solution in both the test tube. Then examine the colour in tube containing test sample. If the blue colour appears in test sample containing tube then the test is positive it means the starch is presence in the given sample [8].

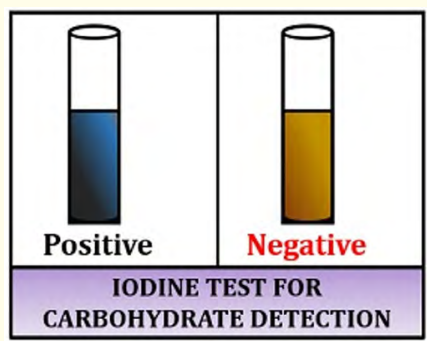

Figure 6: Iodine test.

https://biologyreader.com/qualitative-analysis-of-carbohydrate.html 


\section{Barfoed's test}

Barfoed's test mainly used for detecting the presence of monosaccharides or disaccharides in the given sample.

\section{Principle}

The reduction of cupric acetate by reducing monosaccharides and disaccharides is the base of Barfoed's test reaction. Cupric acetate is reduced to cuprous oxide, which results in a brick red colour precipitate. Monosaccharides often react in 1-5 minutes, resulting in a crimson precipitate. The reducing disaccharides, on the other hand, take much longer to produce a red precipitate, taking anywhere from 7 to 12 minutes. Because disaccharides must first be hydrolyzed before reacting with the reagent like cupric acetate to form cuprous oxide, so the reaction of cupric acetate with disaccharides is slower [16].

$$
\begin{aligned}
& \left(\mathrm{CH}_{3} \mathrm{COO}\right)_{2} \mathrm{Cu}+2 \mathrm{H}_{2} \mathrm{O} \rightarrow 2 \mathrm{CH}_{3} \mathrm{COOH}+\mathrm{Cu}(\mathrm{OH})_{2} \\
& \text { Cupric acetate Cupric hydroxide } \\
& \mathrm{Cu}(\mathrm{OH})_{2} \rightarrow \mathrm{CuO}+\mathrm{H}_{2} \mathrm{O}
\end{aligned}
$$

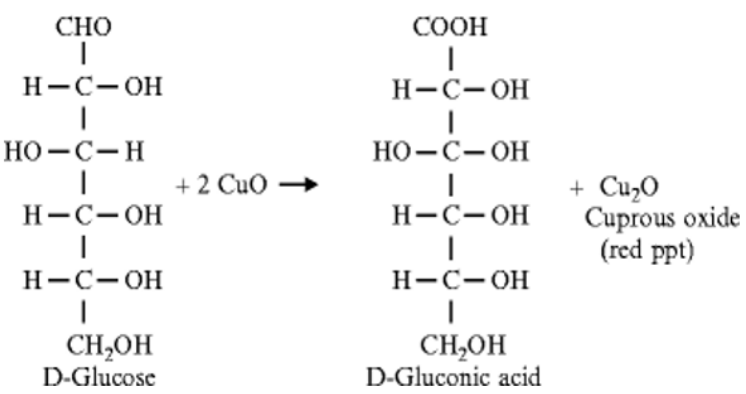

Figure 7: Mechanism of barfoed's test. https://link.springer.com/chapter/10.1007/978-1-4419-9785-2_5

\section{Reagent}

Barfoed's reagent, Test sample.

\section{Procedure}

In a one test tube, $1 \mathrm{ml}$ of test sample is placed. $3 \mathrm{ml}$ of barfoed's reagent is added in the given test tube. Then the solution is boiled for up to 3 minutes in a boiling water bath. Allow it to cool down. Then observe the formation of reddish colour precipitate which indicated the positive result for the test sample [8].

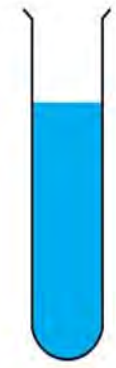

Solution remains blue
Red precipitate is formed

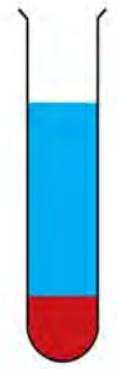

Figure 8: Barfoed's test.

https://noteshippo.com/barfoeds-test-protocol-principleprocedure-result-applications/

\section{Resorcinol (Seliwanoff's test)}

Resorcinol test is use for the differentiation between sugars that have ketone group (ketose) and sugars that have an aldehyde group (aldoses) [24].

Principle

To discriminate between aldoses and ketoses, Seliwanoff's test is performed. When ketoses are treated with conc. Acid like $\mathrm{HCl}$, they dehydrate more quickly, yielding furfural derivatives, and when they are condensed with resorcinol, they yield cherry red complex. Fructose, sucrose and other keto-containing sugars will answer the test.

Reagent

Seliwanoff's reagent, Test sample.

\section{Procedure}

Take $1 \mathrm{ml}$ of test sample in a test tube and $1 \mathrm{ml}$ of distilled water in a control tube. In both test tubes, add 3ml of Seliwanoff's reagents. For 1-2 minutes, place the test tubes in a water bath. Keep an eye out for the appearance of a reddish colour which indicates positive result [16].

\section{Fehling's test}

This test use to distinguish between the presence of aldehydes and ketones in carbohydrates. Ketones sugars other than alphahydroxy-ketone do not respond in the fehling's test [5]. 


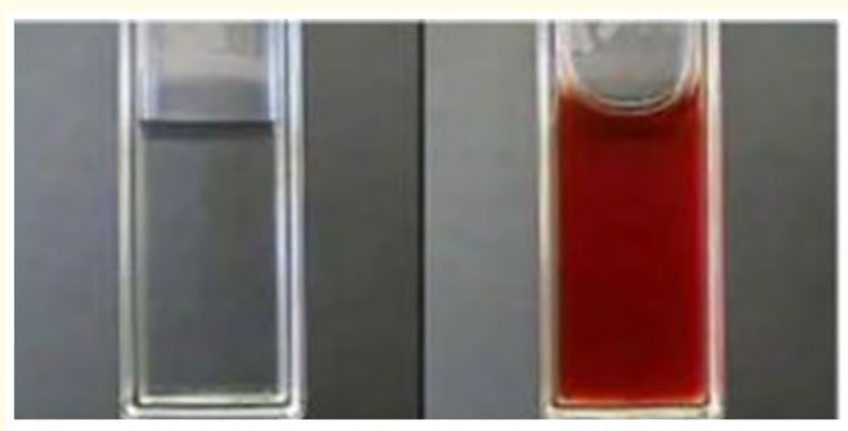

Negative Seliwanoff's test Positive Seliwanoff's test

Figure 9: Seliwanoff's test.

https://noteshippo.com/seliwanoffs-test-for-cane-sugar-principle-procedure-result-limitations

\section{Principle}

One of the most sensitive tests for detecting reducing sugars is Fehling's test. Fehling's reagents are made up of two different solutions. Solution A and solution B. Aqueous copper sulphate is in Fehling's solution A, and alkaline sodium potassium tartarate is in Fehling's solution B (Rochelle salt). The chelating agent in this reaction is Rochelle salts (sodium potassium tartarate). Before the test, these two solutions are combined in an equal proportion. The aldoses in the Fehling's solution bistartarocuprate (II) complex oxidize to the appropriate aldonic acids when heated insoluble yellow or red-colored precipitate form during the process. The complex's copper (II) ions are reduced to an on the other hand, ketones are oxidised to produce shorter acid chains. By generating a bistartarocuprate (II) complex, the tartrate ions prevent the development of insoluble $\mathrm{Cu}(\mathrm{OH})_{2}$ from the reaction of copper sulphate and sodium hydroxide in the solution. This combination slowly releases cupric ions for reduction, preventing black cupric oxide production. Fehling's solution generates a black cupric oxide precipitate when heated in the absence of reducing sugars [24].

\section{Reagent}

Fehling's Solution A: Dissolve $7 \mathrm{gm}$ of $\mathrm{CuSO}_{4} 7 \mathrm{H}_{2} \mathrm{O}$ in $100 \mathrm{ml}$ water. Fehling's Solution B: Dissolve $24 \mathrm{gm}$ of KOH and $34.6 \mathrm{gm}$ of potassium sodium tartrate in $100 \mathrm{ml}$ water. Mix both the solution and prepare Fehling's solution, Test sample [21].

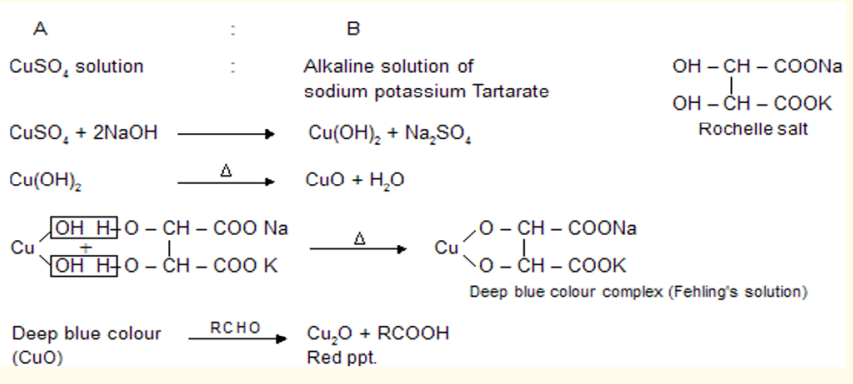

Figure 10: Mechanism of fehling's test.

https://www.onlinebiologynotes.com/fehlings-test-objectiveprinciple-reagents-procedure-and-result/

\section{Procedure}

$1 \mathrm{~mL}$ of a given sample should be placed in a clean, dry test tube. The test samples should have a concentration of $5 \%(w / v)$. In a separate tube, control $1 \mathrm{~mL}$ of pure water. Add a few drops of Fehling's reagent to both tubes and vortex them together. Allow 1-2 minutes for the test tubes to soak in the water bath. Examine how the colour appears in the test tubes. Make a note of the colour appearance in the test tubes. The presence of reducing sugars and the formation of a reddish-brown precipitate suggest a favourable result $[5,21]$.

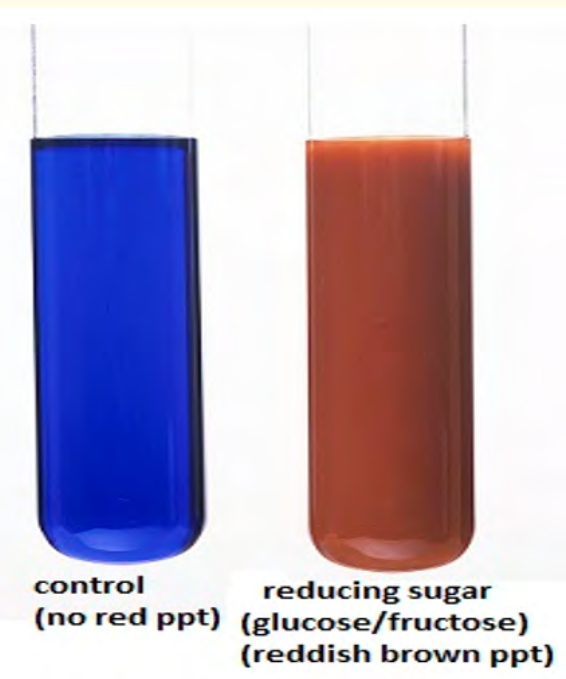

Figure 11: Fehling's test. https://biocheminsider.com/fehlings-test/ 
Quantitative analysis of carbohydrate

There are number of quantitative tests are available. The method mostly depend upon the type of sugar whether it is reducing sugar or not. This method use for the measurement of total carbohydrate present in the given test sample. Here, some of quantitative method is mentioned below.

\section{Anthrone test}

Anthrone test is used to determine and quantify carbohydrates in a variety of samples such as milk, blood serum, and its variations.

\section{Principle}

The concentrated acid in the Anthrone reagent first hydrolyzes carbohydrate into component monosaccharide if it is present in the form of free carbohydrate as poly- or monosaccharide or bound as in a glycoprotein or glycolipid. The concentrated acid also catalyses the dehydration of monosaccharides, resulting in furfural (from pentoses) or hydroxyl furfural (from hexoses). Anthranol, the enol tautomer of anthrone, is the active form of the reagent, which combines with the carbohydrate furfural derivative to produce a green colour in dilute solutions and a blue colour in concentrated solutions, which can be detected colorimetrically. The blue - green solution shows absorption maximum at $620 \mathrm{~nm}[13,20]$.

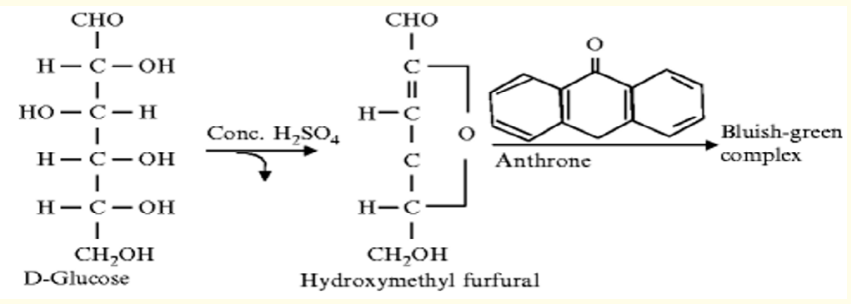

Figure 12: Mechanism of Anthrone test. https://link.springer.com/ chapter/10.1007/978-1-4419-9785-2_5

Reaction

Hydrolysis of polysaccharides to monosaccharide

Polysaccharide $\rightarrow$ Monosaccharides

Dehydration of monosaccharides to furfural

Monosaccharide $\rightarrow$ Furfural
Reaction of furfural with naphthol

Furfural + Anthrone reagent (naphthol) $\rightarrow$ Blue-green complex.

Reagents

Anthrone reagent, sugar stock solution, sample.

\section{Procedure}

First take varied volume of sugar solution (in $\mu \mathrm{l}$ ) from the given stock solution into a succession of test tubes and make up the volume to $1 \mathrm{ml}$ with distilled water. Then take suitable volumes of unknown sample and make up final volume to $1.0 \mathrm{ml}$ distilled water. In each tube, add $5 \mathrm{ml}$ of anthrone reagent and vortex thoroughly to mix. Cool test tubes. Cover the tubes with caps on top and incubate for 17 minutes at $90^{\circ} \mathrm{C}$ or 10 minutes in a boiling water bath. Cool the tubes to room temperature before comparing the optical densities of the solutions to a blank at $620 \mathrm{~nm}$. Make an absorbance vs. sugar concentration standard curve to determine quantity of sugar in the unknown sample [20].

\section{DNSA (Dinitrosalicylic acid) method}

DNSA is an aromatic compound that reacts with react with reducing sugars to estimate the amount of carbohydrates.

\section{Principle}

3, 5- Dinitrosalicylic acid (DNSA) that forms 3-amino-5-nitrosalicylic acid (ANSA) when it combines with reducing sugars [with a free carbonyl group $(\mathrm{C}=0)$ ]. The aldehyde functional group (in glucose) and the ketone functional group (in fructose) are both oxidised in this process. DNSA is reduced to ANSA, which under alkaline condition is transformed to a reddish brown colored complex. The absorbance is measured at $540 \mathrm{~nm}$ [18].

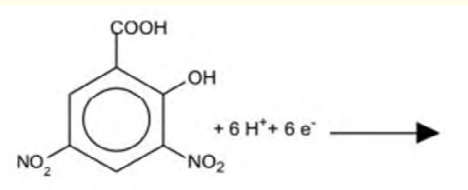

3, 5 Dinitrosalicylic acid (DNSA)

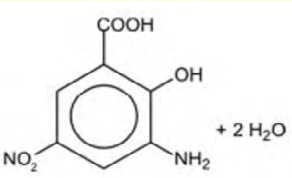

3- amino- 5 nitrosalicylic acid (ANSA)
Figure 13: Mechanism of DNSA (Dinitrosalicylic acid) method. https://noteshippo.com/dinitrosalicylic-acid-method 


\section{Reagents}

DNSA reagent, standard sugar solution, $40 \%$ potassium sodium tartrate, test sample.

\section{Procedure}

Dilution of sugar standard (in $\mu \mathrm{l}$ ) with various concentration made by transferring respective quantity of sugar from the standard sugar solution and by adding distilled water adjusting it to a total volume of $200 \mu \mathrm{l}$. In each of test tubes, add $0.5 \mathrm{ml}$ of DNSA reagent. Mix thoroughly. Allow 15 minutes in a boiling water bath. Then, mix with $0.5 \mathrm{ml}$ of a $40 \%$ potassium sodium tartrate (Rochell's Salt) solution. Using a spectrophotometer set to $540 \mathrm{~nm}$ records the absorbance and find sugar concentration of test sample from standard curve absorbance $\mathrm{v} / \mathrm{s}$ sugar concentration in $\mu \mathrm{g} / 200 \mu \mathrm{l}[18]$.

\section{Phenol sulphuric acid method}

The portion of neutral sugar in oligosaccharides, proteoglycans, glycoproteins, and glycolipids is most commonly determined using this method.

\section{Principle}

In the presence of a strong acid, carbohydrates (simple sugars, oligosaccharides, polysaccharides, and their derivatives) is dehydrated to hydroxymethy furfural that condense with phenol to produce stable yellow-gold compounds that could be spectrophotometrically quantified at $490 \mathrm{~nm}$ [17].

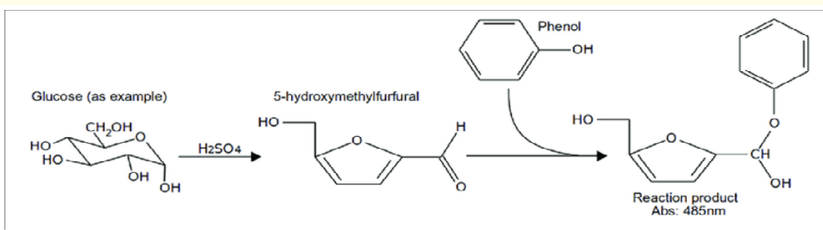

Figure 14: Mechanism of phenol sulphuric acid method.

https://www.researchgate.net/figure/Example-reaction-ofphenol-sulfuric-acid-assay-with-glucose_fig5_346996064

\section{Reagents}

$5 \%$ phenol solution, concentrated $\mathrm{H}_{2} \mathrm{SO}_{4}$, standard sugar solution, test sample.

\section{Procedure}

Dilutions of sugar standards with various concentrations (in $\mu \mathrm{l}$ ) can be made by transferring the appropriate amount of sugar from the standard sugar solution and adjusting the total volume to $200 \mu \mathrm{l}$ with distilled water. Fill each tube with $0.2 \mathrm{ml}$ of a $5 \%$ phenol solution. Then add $1 \mathrm{ml}$ of concentrated Sulphuric acid and well mix it. Following 10 minutes, mix the contents of the tubes and place in a water bath about $25-30^{\circ} \mathrm{C}$ for 20 minutes. Read the absorbance at $485 \mathrm{~nm}$ and determine the sugar content in the test sample from standard curve absorbance v/s sugar concentration in $\mu \mathrm{g} / 200 \mu \mathrm{l}$ $[17,18]$.

\section{Nelson Somogyi's method}

Using copper reagents and arsenolmolybdate, the Nelson-Somogyi method is used to quantify reducing sugar. For sugar estimation, reducing nature of sugar is used for reduction of metallic salts under alkaline condition in boiling state.

\section{Principle}

This method is based on oxidation- reduction reaction. When reducing sugars are heated with alkaline copper tartrate, the copper is converted from cupric to cuprous, forming cuprous oxide. Later, cuprous oxide is reacting with arsenomolybdate reagent to produce molybdenum blue. The intensity of blue color is measured using colorimeter at $520 \mathrm{~nm}$. (To minimize the entry of atmospheric oxygen into the solution, which can cause reoxidation of cuprous oxide, sodium sulphate is added in the reaction mixture) [21,23].

\section{Reagents}

Alkaline copper tartrate solution, Nelson's Arsenomolybdate reagent, working standard sugar solution, test sample.

\section{Procedure}

Take different aliquots of working standard sugar solution from 0.1 to 1.0 . Make up the final volume to $2.0 \mathrm{ml}$ with distilled water in each tube and mix well. To each tube, add $1 \mathrm{ml}$ of alkaline copper tartrate reagent. Place the tubes in boiling water and let them for 10 minutes. After the tubes have cooled, add $1 \mathrm{ml}$ of arsenomolybolic acid reagent to each one. Measure the intensity of color at 520 $\mathrm{nm}$ and find unknown sample concentration from standard curve OD v/s sugar concentration $(\mu \mathrm{g})[23]$. 


\section{Conclusion}

The quantitative analysis of carbohydrates is detected based on the reagent's utilisation and the reaction between the test sample and reagent. The reaction of the test material with the chemical reagent produces a distinct colour, which can be used to determine whether or not carbohydrates are present. According to all above quantitative test of carbohydrate analysis, it is important to determine the type and concentration of carbohydrate in foods for a number of purpose. Quantitative method like phenol sulphuric method which is example of colorimetric method is widely use for the determination of total concentration of carbohydrates. The no. and variety of techniques and strategies available continues to grow rapidly and the choices facing an analyst embarking on the project involving carbohydrate analysis.

\section{Acknowledgement}

We thankful to our mentor Zalak Rathod (SRF), Dr. Meenu Saraf (HOD) and DIST-FIST Department of Microbiology and Biotechnology, University School of Sciences, Gujarat University Ahmedabad Gujarat India to give us such an opportunity and guidance.

\section{Conflict of Interest}

Authors have no conflict of interest.

\section{Bibliography}

1. Başkan K S., et al. "Spectrophotometric total reducing sugars assay based on cupric reduction". Talanta 147 (2016): 162168.

2. BeMiller J N. "Carbohydrate analysis". In Food analysis. Springer, Boston, MA (2010): 147-177.

3. Benedict S R. "A reagent for the detection of reducing sugars". Journal of Biological Chemistry 5.5 (1909): 485-487.

4. Brummer Y and Cui S W. "Understanding carbohydrate analysis". Food Carbohydrates: Chemistry, Physical Properties and Applications (2005): 1-38.

5. Daniels R., et al. "The Fehling and Benedict tests". Journal of Chemical Education 37.4 (1960): 205.

6. Doutre D A., et al. "Spectrophotometric methods to determine carbohydrates in soil". Soil Biology and Biochemistry 10.6 (1978): 457-462.
7. Ebell L F. "Variation in total soluble sugars of conifer tissues with method of analysis". Phytochemistry 8.1 (1969): 227-233.

8. Elzagheid, M. I. "Laboratory activities to introduce carbohydrates qualitative analysis to college students". World Journal of Chemical Education 6.2 (2018): 82-86.

9. Fleischer H. "The Iodine Test for Reducing Sugars-A Safe, Quick and Easy Alternative to Copper (II) and Silver (I) Based Reagents". World 7.2 (2019): 45-52.

10. Foulger J H. "The use of the Molisch ( $\alpha$-naphthol) reactions in the study of sugars in biological fluids". Journal of Biological Chemistry 92.2 (1931): 345-353.

11. Garriga M., et al. "Determination of reducing sugars in extracts of Undaria pinnatifida (harvey) algae by UV-visible spectrophotometry (DNS method)". Desarro. E INNOVACIÓN EN Ing (2017): 444.

12. Hall MB. "Methodological challenges in carbohydrate analyses”. Revista Brasileira de Zootecnia 36 (2007): 359-367.

13. Katoch R. "Carbohydrate Estimations". In Analytical Techniques in Biochemistry and Molecular Biology. Springer, New York, NY (2011): 67-76.

14. Malherbe J S and Meyer C J. "A mini-qualitative carbohydrate analysis session". Journal of Chemical Education 74.11 (1997): 1304.

15. Masuko T., et al. "Carbohydrate analysis by a phenol-sulfuric acid method in microplate format". Analytical Biochemistry 339.1 (2005): 69-72.

16. Mishra T K. "General Tests of Carbohydrates and their Identification". Elsevier Health Sciences (2019).

17. Nielsen S S. "Total carbohydrate by phenol-sulfuric acid method". In Food analysis laboratory manual. Springer, Cham (2017): 137-141.

18. Nos P. “HiPer $®$ Carbohydrates Estimation Teaching Kit (Quantitative); product code: HTBC003; number of experiments that can be performed: 10; duration of experiment". DNSA method, 1.

19. Piccolo A., et al. "A comparison of acid hydrolyses for the determination of carbohydrate content in soils". Communications in Soil Science and Plant Analysis 27.15-17 (1996): 2909-2915.

20. Sadasivam S. "Biochemical methods". New Age International (1996). 
21. Saravanan T S and Ravindranath M H. "Total free sugars, reducing sugars and glucose". CMFRI Special Publication 7 (1981): 17-21.

22. Somogyi M. "Determination of reducing sugars by NelsonSomogyi method". Journal of Biological Chemistry 200 (1952): 245.

23. UKEssays. "Qualitative Tests Used For Carbohydrates Biology Essay" (2018).

24. Yemm E W and Willis A. "The estimation of carbohydrates in plant extracts by anthrone". Biochemical Journal 57.3 (1954): 508-514.

\section{Assets from publication with us}

- Prompt Acknowledgement after receiving the article

- Thorough Double blinded peer review

- Rapid Publication

- Issue of Publication Certificate

- High visibility of your Published work

Website: www.actascientific.com/

Submit Article: www.actascientific.com/submission.php

Email us: editor@actascientific.com

Contact us: +919182824667 